\title{
TRAGEDIA Y VERDAD DE ANTONIO GRAMSCI
}

\author{
Francisco Fernández Buey
}

$\mathrm{H}$ ace algunos años que Antonio Gramsci se convirtió en el pensador italiano más repetidamente citado en las publicaciones mundales de humanidades y ciencias sociales. Sin duda, esto se debe al gran interés que han despertado en muchos países del mundo dos colecciones de escritos suyos: los treinta y tres cuadernos que redactó durante el largo período carcelario al que fue condenado por el fascismo mussoliniano y el más de medio millar de cartas que, desde aquellas prisiones, envió a familiares y amigos entre 1926 y 1937.

Antes de ser detenido y encarcelado, entre el comienzo de la primera guerra mundial y 1926, Antonio Gramsci había desarrollado una intensa actividad como crítico de la cultura y hombre político revolucionario en Turín, Moscú, Viena y Roma. Testimonio de aquella vida de febril dedicación a la política alternativa, a la causa del comunismo (en una Europa que se debatía entre la guerra y la revolución), son los seis volúmenes en que han sido agrupados los escritos gramscianos de esa época. En 1921, cuando se fundó el partido comunista de Italia, Antonio Gramsci era conocido como teórico de la experiencia sociopolítica alternativa más interesante del siglo $X X$ en la península, la experiencia de los consejos de fábrica torineses que habían llegado a ocupar por algún tiempo las instalaciones de la empresa FLAT.

Entre 1919 y 1922 Gramsci escribió un considerable número de piezas políticas notables en los periódicos socialistas y comunistas 
de la época, en La città futura, en Avanti, en Il grido del popolo y, sobre todo, en L'Ordine Nuovo, semanario del que fue animador y director. En L'Ordine Nuovo semanal Gramsci hizo un periodismo político nuevo: informado, culto, polémico y veraz a la vez; un periodismo político que fue apreciado no sólo en los medios socialistas, sino también entre liberales y libertarios de Turín. La fama de L'Ordine Nuovo llegó a España, donde Joaquín Maurín escribía ya sobre Gramsci por aquellos años.

Aquel Gramsci joven, muy espontáneo en la consideración de la actividad política, acusado de bergsoniano, de soreliano y de voluntarista por los propios compañeros de entonces, idealista en lo moral, duro crítico de los sindicatos existentes (a los que consideraba parte de la cultura establecida bajo el capitalismo) fue uno de los redescubrimientos del movimiento juvenil antiautoritario europeo a finales de la década de los sesenta. Y se comprende. Pues algunos de los escritos gramscianos de aquellos años tienen la fuerza político-moral y la calidad literaria de las mejores cosas del joven Lukács o del joven Korsch, por mencionar a dos de los más apreciados teóricos marxistas de los años de entreguerras, tantas veces mencionados también por los jovenes del 68 .

En una carta escrita a Giuseppe Prezzolini el 25 de junio de 1920, Piero Gobetti ha dejado este sugestivo retrato del joven Gramsci teórico de los consejos de fábrica:

"Gramsci ha dividido su actividad entre los estudios y la propaganda política. Es curioso que se haya visto absorbido por la política cuando en la Universidad se contentaba con agudas y sutiles investigaciones de glotología. /... / Le animaba y le anima un gran fervor moral, un tanto desdeñoso y pesimista, por lo que cuando se habla con él por primera vez da la impresión de que tiene una visión escéptica de la vida. /.../ Intransigente, hombre que toma partido, a veces de forma casi feroz, es crítico también con los propios compañeros, y no por polemizar en lo personal o en lo cultural, sino por una insaciable necesidad de ser sincero".

El joven Gramsci, que había interpretado los acontecimientos del octubre ruso de 1917 como una revolución contra El capital de Marx, intuyó varias de las contradicciones por las que estaba pasando la construcción del socialismo en la Unión Soviética ya al 
inicio de los años veinte; contradicciones que luego, con el tiempo, han resultado decisivas a la hora de explicar la crisis de aquel sistema.

La interpretación gramsciana de la revolución rusa como una rebelión, $\tan$ inevitable como voluntarista, que, contra las apariencias, entra en conflicto con las previsiones del primer volumen de El capital, fue tan atípica como sugerente y, en el fondo, como se ha visto, acertada. Gramsci, que no llegó a conocer la evolución de las opiniones del viejo Marx sobre la comuna rusa, ha sido uno los primeros comunistas en darse cuenta de la dimensión del problema político-social implicado por una situación completamente nueva en la historia de la humanidad, a saber: la situación de un proletariado que no tenía apenas nada que llevarse a la boca y que, sin embargo, resultó ser hegemónico, en un océano de campesinos, durante el proceso revolucionario abierto por la guerra mundial; la situación paradójica, en suma, de una clase social que nada tiene, excepto - nominalmente - el poder político. Una contradicción histórica ésta, que quizás sólo resulta de verdad comprensible cuando se la analiza en términos parecidos a los que los que utilizaron Walter Benjamin y Bertolt Brecht al hablar de la Unión Soviética de entonces como de un "pez cornudo".

La pregunta interesante, que vale la pena hacerse hoy en día, en una situación psicosociológica tan cambiada —cuando ya hay quien va diciendo por ahí que de la historia comunista no quedará ni rastro- es ésta: por qué motivos un hombre tan sensible y crítico como Gramsci, que se daba cuenta de las contradicciones internas de aquel sistema surgido de la Revolución de Octubre, no sólo despreció la argumentación socialdemócrata de la época (según la cual el atraso económico de Rusia hacía inviable el triunfo de la revolución socialista alli), sino que, además, exaltó aquella revolución, la revolución contra El capital (con sus contradicciones incluidas), ateniéndose al hecho de que ésta expresaba el anhelo de un orden nuevo que brota de los de abajo, de los asalariados explotados aliados con los campesinos pobres. Por qué, en definitiva, prefirió Gramsci aquel "pez cornudo" al viejo orden capitalista, en sus diferentes formas, dominante en otros países de Europa.

La pregunta no es gratuita; tiene una connotación singular para los más jóvenes, pues, sin una respuesta cumplida y suficiente a la 
misma, podría parecer que, en efecto, la historia del movimiento comunista modemo no ha sido otra cosa que una equivocación integral, en la que los hombres (incluido Gramsci) habrían caído sólo por ignorancia o sólo por maldad. Hay que reconocer que una pregunta así tiene mucho que ver con el cambio de los tiempos. Los tiempos en que los jóvenes rebeldes europeos redescubrían y amaban al joven Gramsci consejista pasaron ya. Y es lógico y natural que ahora, en los tiempos sombríos que corren, en estos tiempos en los que el mundo parece estar caminando, a la inversa, desde la contrarrevolución cultural y política hacia las nuevas guerras del opio e interétnicas, se recuerde, de manera particular, no a aquel Gramsci joven y voluntarista, sino al Gramsci maduro que, en su tragedia personal, encaja reflexivamente la derrota de la revolución proletaria en la Europa central y occidental. No en balde el crítico e historiador británico del arte, John Berger, nos proponía hace poco tiempo, en una excelente colección de ensayos titulada $E l$ sentido de la vista, un ejercicio tan sugestivo como lo es el de pensar un marxismo trágico en el que, por así decirlo, Marx se pone a leer comprensivamente a Leopardi sin por ello perder la pasión tranformadora que en su día le llevó a escribir la onceava tesis sobre Feuerbach.

Se podría decir que en los tiempos que corren tiene más sentido que nunca una reflexión acerca de la tragedia del hombre Gramsci, acerca de una tragedia que sustancia muy bien la más general tragedia del movimiento comunista modemo en la Europa central y occidental, la de los revolucionarios sin revolución.

Poner el acento en la tragedia del hombre Gramsci y reflexionar sobre ella no tiene por qué implicar necesariamente invertir por completo el optimismo histórico, que fue característico de todos los marxismos, para reemplazarlo por una visión sólo pesimista de la historia y de la vida de los hombres en sociedad; más bien significa atenerse a lo que fue el punto de vista íntimo del propio Gramsci, el cual consideraba que "optimismo" y "pesimismo" son simples estados de ánimo transitorios, insuficientes, por tanto, para caracterizar la estructura profunda de ese centro de anudamiento de relaciones múltiples que es el individuo humano. Significa, sobre todo, repensar algunos cabos sueltos de la vida y de la obra de Gramsci que, en las cartas escritas desde la cárcel, aparecen 
tentativamente, o como mera sospecha, y que hoy, a la luz de las nuevas preocupaciones de las gentes que siguen manteniendo la idealidad emancipatoria cobran, por así decirlo, otra dimensión.

Desde esta perspectiva de ahora, que pone el acento en la idea del comunismo como horizonte y en la necesidad de revolucionarizar la vida cotidiana empezando por las relaciones interpersonales, ¿qué decir, por ejemplo, de aquel encuentro final, en la Formia de 1935, entre los dos grandes del comunismo italiano de entreguerras (que, además, habían sido amigos y compartido el pan y la sal en el destierro de Ustica), represaliados ambos, aunque no en la misma medida, por el fascismo mussoliniano, el sardo Gramsci y el napolitano Bordiga? ¿Qué decir de aquel encuentro resuelto, por lo que sabemos a través del relato que nos ha dejado Giuseppe Fiori, con un escueto "ciao Nino", "ciao Amadeo"? ¿Es eso todo lo que tienen que comunicarse en un momento así, después de tantos años de lucha en común y de tantos otros de no verse, dos personas cuya dignidad moral está más allá de toda duda y que habían sacrificado sus vidas a la construcción del orden nuevo y del hombre nuevo?

Parece de toda evidencia que es desde la reflexión sobre situaciones así, tan repetidas en los años de la III Internacional (y que cuadran muy bien con la meditación de Brecht, en su poema dedicado $A$ los por nacer, sobre aquella generación de comunistas que "no pudieron ser amables" y que "contemplaban la naturaleza con impaciencia") como se puede preconizar ahora, sin avergonzarse, la necesidad de una específica educación sentimental en el marco de la cultura socialista.

Gramsci intuyó en más de una ocasión el desierto en el que acaba resolviéndose una cultura politicista, la aridez de la actividad sólo política, la insatisfacción de una vida de revolucionario profesional que entrega todas las horas de su existencia a la (justa) causa del comunismo, sin tiempo restante para el cultivo de otras dimensiones de la personalidad, para mejorar moderadamente en las relaciones íntimas, cotidianas. También él vivió la tragedia del revolucionario saltafronteras que mira con impaciencia la naturaleza y que no puede ser amable, amistoso, en la agudización de la lucha entre las clases. Tal vez como ningún otro de los revolucio- 
narios de su época sintió Gramsci el salto sin transición desde una concepción voluntarista de la negación del tiempo a la consideración trágica del tiempo como mero pseudónimo de la vida misma.

Para hacerse una idea de lo que pudo llegar a representar en la cultura comunista de entonces este brechtiano contemplar la naturaleza con impaciencia, tal vez lo más indicado sea comparar dos pasos de la correspondencia de Gramsci separados por poco más de un año. El 15 de agosto de 1925 nuestro hombre escribe a Julia Schucht:

"Durante los últimos tiempos he danzado mucho, he visto parajes que, según dicen, son bellísimos, paisajes que, al parecer, son admirables, tan admirables que los extranjeros vienen de lejos para contemplarlos. Por ejemplo, he estado en Miramare, pero me ha parecido una errada fantasía de Carducci: las blancas torres se me presentaban como chimeneas acabadas de blanquear con argamasa; el mar tenía un color amarillo sucio, porque los peones que construían un camino habían echado en él toneladas de basuras; el sol me dio la impresión de un calorífero fuera de estación".

Gramsci escribía sobre la "errada fantasía de Carducci" todavía en libertad, consciente, sin embargo, de "haber perdido el gusto por la naturaleza" y de estar convirtiéndose en un ser "apático" debido a la existencia sólo política que llevaba entonces y a la melancolía producida por la ausencia de la mujer a la que amaba. En cambio, unos meses más tarde, el 15 de enero de 1927, confinado en Ustica después de la detención, a pesar del evidente empeoramiento de la situación personal, de que Yulca Schucht aún sigue lejos y de los malos augurios inevitables en un preso político de un régimen autoritario, la mirada de nuestro hombre sobre la naturaleza es otra, muy otra:

"Tenemos a nuestra disposición una hermosísima terraza desde la que admiramos el mar sin fín durante el día y un magrúfico cielo por la noche. Como el cielo está limpio, sin los humos de la ciudad, podemos gozar estas maravillas con la máxima intensidad. Los colores del agua del mar y del firmamento son realmente extraordinarios por su variedad y por su profundidad: he visto aquí arco iris únicos en su género".

El contraste entre los dos pasos es llamativo. La paciencia, la 
serenidad, para la contemplación de la naturaleza llega, paradójicamente, cuando Gramsci ha perdido una libertad de movimientos que, por otra parte, no le permitía pararse en observaciones ni en descripciones de este tipo. Se ve ahí con toda claridad en qué estaba pensando Gramsci al hablar del desierto de lo sólo político. No es ninguna casualidad, dicho sea de paso, que las cartas redactadas por Gramsci en Ustica sean tal vez las más distendidas de las que escribió desde que dejara a Julia Schucht en Moscú. Quien haya conocido la dureza de la lucha política clandestina unida al sentimiento de tristeza que produce el alejamiento de la persona amada sabe, puede saber, que hasta el destierro y la cárcel resultan, en los primeros momentos, relajantes, un lenitivo contra el desdoblamiento del hombre entre el deber y el querer.

En sus relaciones con Yulca ya antes del encarcelamiento, en Moscú, o desde Viena y Roma, Antonio había atribuído a veces sus dificultades de comunicación, la incomunicación parcial, o la dificultad para establecer un vínculo interpersonal estable con la mujer amada, a su propia contención sentimental, aludiendo incluso, humorísticamente, al viejo tópico regionalista del sardo que es como una isla en la isla. Pero Gramsci sabía que esas complicaciones sentimentales iban de la mano con el empobrecimiento que representa la dedicación exclusiva a la actividad política, incluso cuando ésta intenta ser, como era el caso, ética de lo colectivo, y no mera parodia de la participación ciudadana en los asuntos de la polis. Mientras conservó el humor para la autoironía fresca, que fue uno de los rasgos de su carácter en la época precarcelaria, Gramsci escribió no pocas bromas amenas sobre la vida del revolucionario profesional en "un mundo grande y terrible". Por ejemplo, desde Viena, en 1924. Luego, ya en la prisión de Turi de Bari, las cosas iban a cambiar: la actitud de otros profesionales de la política menos dados todavía a la comprensión de los sentimientos íntimos del prójimo (aunque seguramente tan bienintencionados como el propio Gramsci), el progreso de la enfermedad (del sufrimiento y del dolor, claro está), y la "carcelitis" (con el agudizarse de un sentimiento de casi constante sospecha) serian factores que habrían de contribuir a agriarle aquel buen humor que en 1924 todavía le permitía celebrar con Julia el año nuevo "riéndonos de todos y de todo, con excepción, por supuesto, de 
las cosas serias, que de, todas formas, son ya muy pocas en este mundo grande y terrible".

Espero no ser demasiado unilateral si, al acentuar este tema de la relación entre mundo de la política y mundo de los sentimientos, digo ahora que las Cartas de la cárcel son, tal vez, la más directa y efectiva introducción a la obra del Gramsci pensador y hombre de acción, de un Gramsci que, mientras tanto, se ha ido convirtiendo para nosotros en un clásico de la filosofía política. Hablo de introducción pensando sobre todo en las personas jóvenes que no han llegado a conocer aquella "moda Gramsci", tan vinculada al fenómeno efímero del "eurocomunismo", que se produjo en España inmediatamente después de la muerte de Franco.

Las Cartas de la cárcel son una parte de la correspondencia conocida de Antonio Gramsci; si exceptuamos unas cuantas misivas políticas escritas desde Viena y Roma en 1924-1926, la parte más importante de la correspondencia gramsciana tanto cuantitativa como sustantivamente. Cuando se publicaron por primera vez, diez años depués de la muerte de Gramsci y dos años después del final de la segunda guerra mundial, la expectación ante el contenido de las mismas era grande, y el elogio con el que fueron acogidas, unánime. Benedetto Croce, el entonces indiscutido patriarca de la cultura italiana, tan alejado políticamente de Gramsci, llegó a escribir que las Cartas hacían de su autor "uno de los nuestros", con lo que pretendía llamar la atención de los intelectuales contemporáneos acerca del altísimo contenido ético y literario de aquella correspondencia.

Esta opinión de Croce ha sido repetida en Italia muchas veces, y últimamente, con motivo de las conmemoraciones recientes en 1989 y 1991, por Bobbio y por Garin. Y hay motivos para ello. Desde 1947, fecha en la que se publicó aquella primera edición que incluía 218 cartas, han sido dadas a conocer otras muchas. Las ediciones más recientes de las Lettere dal carcere contienen ya medio millar largo. Y a medida que pasa el tiempo, cuando lo que fue privado puede hacerse público con el amable consentimiento de los familiares, hemos ido conociendo, a través de esta correspondencia, aspectos que todavía en 1947 quedaban ensombrecidos por alusiones en las que se entrecruzan la disidencia política y el malestar afectivo con las angustias y preocupaciones por un proceso 
tuberculoso que acabaría matando a nuestro personaje.

Ahora, gracias a la publicación durante la última década (por Antonio A. Santucci, Giuseppe Fiori, Mimma Paulesu Quercioli y Valentino Gerratana, entre otros) de algunas cartas íntimas que la familia no había hecho públicas todavía, y, sobre todo, gracias a la edición, durante 1991 (por Aldo Natoli y Valentino Gerratana) de la correspondencia que su cuñada, Tatiana Schucht, mantuvo con él o con terceras personas (el economista Piero Sraffa, principalmente) conocemos con todo detalle no sólo la tragedia de aquel hombre en la cárcel, sino también las dimensiones de la misma (incluido el sufrimiento de Julia, su compañera rusa, y de Tatiana, mujeres de las que, habiendo sido, como lo fueron, la última atadura de Gramsci con el mundo, apenas se sabía hasta hace poco otra cosa que el nombre.

El centenario del nacimiento que conmemoramos este año es una buena ocasión para ir más allá de la imagen que en 1947 se tenía del "santo laico", del mártir antifascista muerto en las cárceles de Mussolini. Ir más allá, no, claro está, para ensombrecer, o para romper caprichosamente, esta imagen que tantos visos tiene de verosimilitud (y que seguramente se seguirá manteniendo cuando haya pasado la necesidad de intrumentalizar a Gramsci en términos políticos), sino para añadir otros elementos que, al complicar la ya conocida contradictoriedad interna del personaje, lo engrandecen en cierto modo a él y nos hacen pensar a nosotros, una vez más, que la tragedia del hombre, del individuo hombre, no cabe ni siquiera en el mejor de los clichés.

En efecto, el conjunto de la correspondencia ahora conocida, ya considerable, nos presenta a un Gramsci siempre en polémica con el tipo de separación entre lo público y lo privado que es típico de la cultura moderna, burguesa. El espíritu de la rebelión se mantuvo en él para convertirse en espiritu de la resistencia.

El Gramsci de los últimos años de cárcel, tal como se nos muestra en las cartas a Julia y Tatiana Schucht, parece un hombre cuyo estado de ánimo oscila continuamente entre "el lobo sentimental" y el "oso de las cavernas", para decirlo con dos expresiones que él mismo empleó mucho. En la presentación de la traducción castellana (Barcelona, Crítica, 1990) de las Cartas a Yulca Schucht, he 
escrito que de esta correspondencia sale un Gramsci sugestivo y conmovedor en sus contradicciones y ambigüedades: volitivo, polémico, puntilloso, con una punta de pedantería autoconsciente, con gran capacidad para el autoanálisis, desconfiado hasta la neurosis, sentimentalmente contenido, pero que intenta al mismo tiempo rehacer el mundo primitivo de los sentimientos propios para adaptar este mundo al de una violinista rusa a la que ama y al de una profesora de ciencias naturales, hermana de la anterior, que fue casi.su único contacto con el mundo exterior durante diez años largos.

A través de esta correspondencia; en páginas a veces bellísimas, que conmueven hasta la formación del nudo en la garganta, nos encontramos con la siempre vieja y nueva dignidad del hombre que acepta peligros y persecución, hasta la muerte, por un ideal (éste fue el principal aspecto de las Lettere subrayado por Croce, con razón) Descubrimos ahí la veracidad del intelectual que sigue pensando con la propia cabeza en las condiciones más adversas, aislado en la cárcel y orientándose parcialmente contra los propios amigos naturales, cuya línea política, por lo que sabemos, ya no aceptó nunca desde 1929. Nos impresionamos con la dignidad del varón que, en 1932, convencido de que aún habrá de estar muchos años más en la cárcel y consciente del deterioro que ésta, la cárcel, le está produciendo, comunica a la cuñada su decisión de dejar a Julia, su compañera (con dos hijos suyos, tan sola como él y enferma en Moscú) en libertad, sugiriéndole inopinadamente que rompa los lazos afectivos con aquel "lobo sentimental" condenado a veinte años de cárcel que es él mismo. Una decisión, ésta, por otra parte, indicadora de la complicación de los sentimientos afectivos del individuo, que, con el triste bagaje de la educación sentimental de los varones de entonces (¿y de siempre?), no encuentra las palabras adecuadas para expresar lo que siente sin hérir ( y él no querría herir), por lo que, así, se và ovillando en un mar de sospechas y de confusiones que tornó su humor, antaño alegre, en sarcasmo irascible, o en irritabilidad multiplicada, además, por el dolor $y$ por el sufrimiento que le producen la enfermedad.

En esta correspondencia de Gramsci hallamos también el desesperado intento del padre que apenas conoce a sus dos hijos por influir en la éducación de los mismos, desde lejos, tratando de 
salvar la censura carcelaria, buscando desesperadamente las palabras para anudar lazos con dos niños que se están formando, en la URSS de los inicios del estalinismo, en una cultura muy distinta de la que él mismo había aprendido en la isla de Cerdeña a principios de siglo.

En las Cartas de la carcel encontramos, por último, luminosas indicaciones para entender pasos polémicos de las notas teóricas contenidas en los Cuadernos y para explicar la evolución del programa intelectual de Gramsci en aquel tremendo laboratorio de las ideas que trató de.construir en la cárcel de Turi de Bari y en la clínica de Formia. Por ellas conocemos, por ejemplo, la dificultad que Gramsci tenía para trabajar "desinteresadamente", en la acepción que el término suele adoptar en la vida académico-científica.

Es cierto que en una célebre carta a la cuñada, en la que comunica su plan de estudios en la cárcel, Gramsci manifestó precisamente la intención de aprovechar la circunstancia desfavorable para hacer algo intelectualmente für ewig. Pero sería dermasiado ingenuo tomarse esta declaración al pie de la letra. En la alusión a Pascoli (y a Goethe) que acompaña tal declaración hay, sin duda, una nota de humor negro, de autoironía sobre el propio destino, a la que nuestro hombre fue haciéndose cada vez más aficionado.

Por lo demás, el estilo de Gramsci, el talante de Gramsci, no era el del estudioso desinteresado que se pone a escribir "para siempre", para la eternidad, sino que era más bien el propio de un hombre polémico, que ama y practica el discurso dialógico. En una carta menos citada que la anterior, pero, en mi opinión, más representativa de ese carácter discutidor hasta lo puntilloso ya observado por Gobetti, y que se acentuaría en la cárcel, el propio Gramsci lo ha escrito redondo:

"Toda mi formación intelectual ha sido de tipo polémico. El pensar desinteresadamente me es difícil, quiero decir el estudio por el estudio. Sólo a veces, pero muy raramente, me ha ocurrido meterme en un determinado tipo de reflexiones y encontrar, por así decirlo, en las cosas en sí el interés para dedicarme a su análisis. Ordinariamente me es necesario ponerme en un punto de vista dialógico o dialéctico, pues en otro caso no siento ningún estímulo intelectual. No me gusta tirar piedras al vacío, quiero sentir 
un interlocutor o un adversario concreto. Incluso en la relación familiar quiero dialogar".

Es la súma de este talante dialógico, polémico, y de un estilo tan veraz como directo lo que, si hay suerte, puede hacer de Gramsci una de las lecturas de interés por los jóvenes de los próximos años. Se ha dicho a veces en estos últimos tiempos que el gramscismo lleva camino de convertirse en el marxismo del final del siglo XX. Y es posible que así sea. Uno compartiría sin más tal afirmación si no fuera por las reticencias que obligatoriamente producen hoy en día frases que recuerdan otras que dieron lugar a dogmatismos. Lo. seguro, en cualquier caso, es que los Cuadernos y las Cartas de la cárcel quedarán en la historia del pensamiento como un documento, veraz en el concepto, auténtico en la forma, de la ética de la resistencia. Gramsci selló este documento con palabras escritas a la madre:

"Nunca hablo del aspecto negativo de mi vida, ante todo porque no quiero ser objeto de compasión. He sido un combatiente que no ha tenido suerte en la lucha inmediata. Y los combatientes no pueden ni deben ser compadecidos cuando han luchado, no empujados por la obligación, sino por haberlo querido ellos mismos así, con plena conciencia".

Cuando Gramsci escribió estas palabras a la madre eran tiempos difíciles para los partidarios de la igualdad social y de la libertad política que, además, luchaban por ambas cosas; tiempos de los que el poeta Bertolt Brecht dejó dicho a los por nacer que, en ellos, "no pudimos ser amables". Sin duda, se refería Brecht a los espíritus moralmente fuertes que animaron la ética de la resistencia frente a la barbarie en los años treinta. Y en este sentido la reflexión de Brecht vale también, y sobre todo, para Gramsci. Fue Togliatti, quien al forjar la imagen del mártir antifascista, recordó esta negativa de Gramsci a ser objeto de la compasión de otros, y quien, en algún momento, opuso esta imagen del héroe (que no quiere ser compadecido y que se resiste a solicitar cualquier medida de gracia del dictador) a la del otro fundador del partido comunista de Italia, Amadeo Bordiga, el cual, por aquellas fechas en las que Gramsci agonizaba, ejercía de ingeniero después de haber abandonado momentáneamente toda actividad política. 
Es comptensible que Gramsci no quisiera ser objeto de compasion. Los hombres que se consideran fuertes (y hay numerosas cartas de él que hablan en tal sentido) no suelen hacer mucho aprecio de la piedad cuando el objeto de consideración son ellos mismos.: Y menos cuando escriben a la madre desde la cárcel. Pero el hombre Gramsci, minado por la enfermedad, y confuso a veces por los efectos de lo que llamó la "carcelitis", no siempre pudo componer la figura como lo hace en esta carta a la madre. En otras cartas dirigidas a Tatiana Schucht, la persona que tenía más cerca, fuera de la cárcel, y la que, por tanto, más podía hacer por él en aquellas circunstancias, no sólo se quejó amargamente de su suerte, de aquel destino trágico suyo, sino que a veces llegó a acusar a su corresponsal, injustamente, de no entender lo que él estaba sufriendo por la enfermedad y por la soledad sentimental y política. Por suerte para quienes le conocieron y le trataron, el Gramsci íntimo no era sólo rigor moral y sarcasmo apasionado; fue también una persona a veces tierna y desvalida, aunque, eso sí, seguía parapetándose casi siempre, como durante su infancia en la isla, "tras una máscara de dureza o una sonrisa irónica". Tal vez por ello, a pesar de ser, como somos, gentes de otra época, gentes para las que la noche oscura del fascismo es sólo recuerdo del pasado o temor de futuro, las Cartas de la cárcel siguen haciendo en nosotros el efecto de la catarsis.

Pero no querría terminar sin hacerme, sin haceros, otra pregunta: ¿tampoco ahora, en la nueva fase de la historia de Europa que nos ha tocado vivir, hay que compadecerse del hombre Gramsci? ¿Acaso hay que seguir oponiendo sin matices, como lo hizo Palmiro Togliatti, sus palabras a la madre, su gesto heroico en la cárcel, a la contrafigura de Amadeo Bordiga?

Creo que, desde la perspectiva actual, desde lo que hoy sabemos de la historia del comunismo, la respuesta a esta pregunta tiene que ser negativa. $Y$ no sólo porque ahora conocemos mejor la ambivalencia o contradictoriedad del carácter de aquel Antonio Gramsci que escribe a la madre que no quiere compasión. Ni tampoco porque ahora sabemos más acerca de los razonables motivos por los que Amadeo Bordiga (injustamente expulsado del partido comunista en 1930) quedó fuera de la política en los años de hierro. Hay un motivo aún más fuerte que el mejor conocimiento que 
hoy podamos tener de los protagonistas de aquella historia a la vez tremenda y moralmente sugestiva: la necesidad de reconsiderar a fondo lo que ha sido la educación sentimental, la relación entre sentimientos privados y razón política, en el movimiento comunista y, más en general, en la ya la larga lucha de los humanos en favor de la emancipación.

Madrid,28/XII/1991 